\title{
Summary of methods to calculate the shearing resistance of CFRP
}

\author{
Huaguo Gao ${ }^{1, a^{*}}$, Xiaoguang Cai ${ }^{1, b}$ \\ ${ }^{1}$ School of Civil Engineering, University of Science and Technology Liaoning, Anshan 114051, \\ China \\ agaohuaguo99@163.com, b751954971@qq.com
}

\section{Keywords: CFRP, Shear capacity, The carbon fiber cloth, Summary}

Abstract: This article summarizes the following, based on the blind area of CFRP shear bearing capacity calculation and combined with several calculation methods given by some domestic scholars in recent years. the literature ${ }^{[1]}$ derives the shear strength formula by the product of the elastic modulus and effective strain, which is got by simple fitting methods, of CFRP, the effective stress of CFRP.the literature ${ }^{[4]}$ assumes that the carbon fiber tension occurs only in the fiber direction and considers that in the ultimate state, the fiber strain is less than its Failure strain, then we can use it as a known quantity of the effective strain for fitting to get the shear bearing capacity formula. The difference from the former two is what in the literature ${ }^{[5]}$, introduces the secondary stress influence coefficient due to the situation of reinforcement of the beam secondary stress to correct the CFRP strain for the derivation of its effective stress and shear strength formula.

\section{Introduction}

In recent years, carbon fiber cloth (CFRP), a kind of flexible material, has been widely applied in the field of strengthening concrete structures, due to its high strength but light weight, good corrosion resistance, fatigue resistance and easy construction etc. Our government, china has formally promulgated the "regulations of technology of carbon fiber sheet reinforced concrete structure", in 2003. However, there is still the blind area, especially on its shear capacity calculation; because our country still has no clear and reliable theory of computation on carbon fiber reinforced concrete structures. What is directly contributing to the technology is limited a lot in the actual promotion. Based on the above background, this research summarizes some achievements of domestic scholars in recent years for public reference.

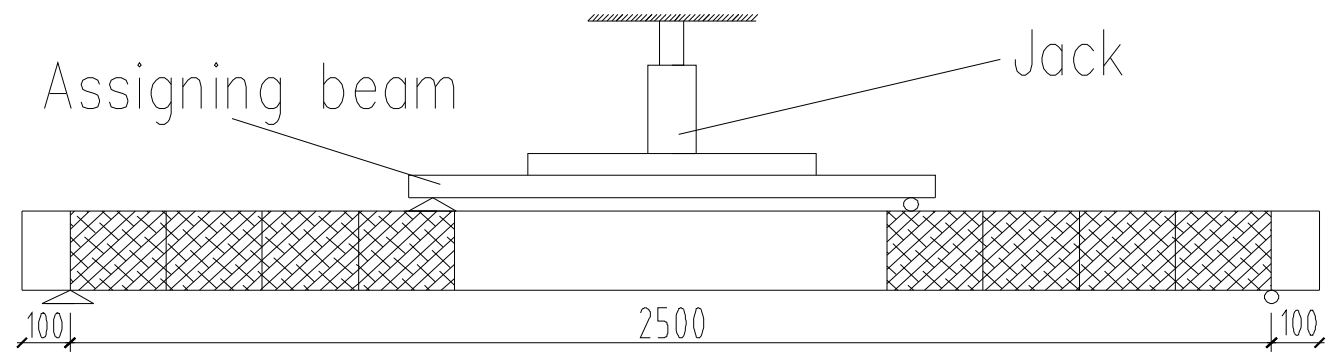

Fig.1. Sketch map of carbon fiber cloth paste 


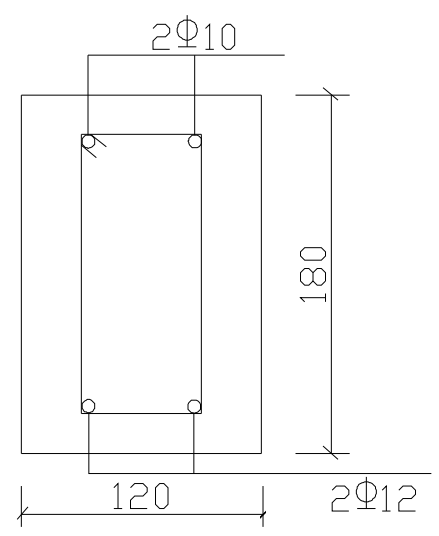

Fig.2. Beam section size

\section{The experimental background overview}

The beam cross section sizes as shown in figure 2, are $180 \mathrm{~mm} \times 120 \mathrm{~mm}$, beam length of $2700 \mathrm{~mm}$, lab loading equipment as shown in figure 1, jack will load the upper beam two concentrated load by assigning beam at a third location, no paste CFRP area for pure bending. Firstly, we calculate the ultimate bearing capacity of beams In accordance with the inclined section bending shear reinforcement from literature ${ }^{[3]}$, then drawing out $50 \%$ of the stirrup, after the concrete is poured and cured; we wrapped CFRP in beam shear zone by using epoxy resin paste.

\section{Introduction to the theory of computing}

Fitting CFRP effective strain simply. Assuming that the function of carbon fiber cloth is similar to stirrup, so it takes a formula for shear theory as follows:

$$
V_{f}=f_{f e} A_{f} h_{f} / s_{f}
$$

Where ' $\mathrm{V}_{\mathrm{f}}$ ' = the shear capacity of carbon fiber cloth. ' $\mathrm{f}_{\mathrm{fe}}$ ' = the effective tensile strength of carbon fiber cloth. ' $A_{\mathrm{f}}$ ' $=$ the area of the carbon fiber cloth belt. ' $\mathrm{h}_{\mathrm{f}}$ ' $=$ the height of the carbon fiber cloth belt. ' $\mathrm{S}_{\mathrm{f}}$ ' $=$ the carbon fiber cloth with spacing.

The key of solving the above type is to determine' $\mathrm{f}_{\mathrm{fe}}$ ', the effective tensile strength of carbon fiber cloth, where ' $\mathrm{f}_{\mathrm{fe}}$ ' equal to the product of the elastic modulus and the effective strain of the carbon fiber cloth. The elastic modulus of carbon fiber cloth is known, the key is the determination of its effective strain. Literature ${ }^{[2]}$ points out: Shear capacity of carbon fiber cloth is associated with its effective bond length; however the effective bond length depends on the thickness of carbon fiber cloth, elastic modulus, the strength of the concrete. Through literature ${ }^{[1]}$ experimental data fits out the effective strain expression ${ }^{[1]}$, as follows:

$$
\varepsilon_{f \mathrm{e}}=0.00001 f_{c}^{3 / 2}\left(\rho_{f} E_{f}\right)^{-1.1299}
$$

From equation (2) can be seen: CFRP effective strain is proportional to the strength of concrete, but inversely proportional to the product of fiber distribution rate and CFRP elastic modulus, what is closer to the truth. Concrete strength is higher, the less prone to deboning, effective strain of 
CFRP greater; the more bonded layers of carbon fiber, the greater the stiffness, more easy to peel, the less effective strain.

In summary, that method established complete CFRP reinforced concrete beam shear capacity formula as follows:

$$
\begin{gathered}
V_{u}=V_{c}+V_{s}+V_{f} \\
V_{f}=0.00001 f_{c}^{\prime}{ }^{3 / 2}\left(\rho_{f} E_{f}\right)^{-1.1299} E_{f} A_{f} h_{f} / s_{f}
\end{gathered}
$$

Where: ' $\mathrm{V}_{\mathrm{c}}$ ' $=$ the shear capacity of concrete. ' $\mathrm{V}_{\mathrm{s}}$ ' $=$ the shear capacity of stirrups. Both can be calculated according to "design of concrete structures" (50010-2011).

Fitting CFRP effective strain considering ' $\varepsilon_{\mathrm{fu}}$ '. Externally bonded carbon fiber can be simulated to the internal stirrup. Besides, assuming tension occurs only in fiber direction. In limit state, the effective strain by fiber direction $\left(\varepsilon_{\mathrm{fe}}\right)$ less than its failure strain $\left(\varepsilon_{\mathrm{fu}}\right)$, therefore the formula (3) can be written as in expression ${ }^{[4]}$ :

$$
\begin{gathered}
V_{f}=\rho_{f} E_{f} \varepsilon_{f e} d_{f} b_{w} \\
\varepsilon_{f e}=0.17\left(f_{c}^{\prime 2 / 3} / \rho_{f} E_{f}\right)^{0.3} \varepsilon_{f u}
\end{gathered}
$$

Where: ' $\varepsilon_{\mathrm{fe}}$ ' $=$ the carbon fibers effective strain; ' $\mathrm{b}_{\mathrm{w}}$ ' $=$ the effective length of the beam; ' $\mathrm{d}_{\mathrm{f}}$ ' $=$ the effective bond length of fiber cloth; ' $\rho_{\mathrm{f}}$ ' $=$ fiber shear enhancement coefficient, $\rho_{f}=\left(2 t_{f} / b_{w}\right)\left(W_{f} / S_{f}\right)$; ' $\mathrm{E}_{\mathrm{f}}$ ' $=$ the elastic modulus of fiber reinforced material. CFRP effective bond length:

$$
L_{e}=e^{6.134-0.58 \ln \left(t_{f} E_{f}\right)}
$$

Where: ' $\mathrm{t}_{\mathrm{f}}$ ' $=$ the thickness of the beam side of the fabric.

Considering the secondary load influence coefficient. Shear capacity expression of CFRP reinforced concrete beam is as follow:

$$
V_{u}=V_{C S}+V_{f}
$$

Where: ' $\mathrm{V}_{\mathrm{CS}}$ ' = the shear contribution of concrete and stirrups, their calculation methods refer to the "design of concrete structures" [3].

Learned from the literature ${ }^{[5]:}$ Calculated CFRP shear force volume without considering the secondary load is generally greater than the measured volume., What is unsafe. Even if some of data are close to the measured values, can lead to overly conservative or waste of material properties. The ideal solutions for the problem is as the literature ${ }^{[5]}$ to propose coefficient by the secondary load, ' $\beta$ '. 


$$
\beta=1-V / V_{u}
$$

Where: ' $\mathrm{V}$ ' $=$ the shear capacity value when Beams are reinforced; ' $\mathrm{V}_{\mathrm{u}}$ ' $=$ the ultimate shear capacity value when Beams are not strengthened.

Based on the literature ${ }^{[6]}$, we get CFRP secondary load Shear Capacity calculation formula is as follows.

$$
V_{f}=883 \beta(\lambda+8.16) \quad\left(\lambda_{E} \eta\right)^{-0.3} b h \rho_{f} E_{f}
$$

Where: ' $\lambda_{\mathrm{e}}$ ' $=$ the shear reinforcement characteristic value, $\lambda_{E}=\rho_{f} E_{f} / f_{t} ;$ ' $\mathrm{f}_{\mathrm{t}}$ ' $=$ for the concrete tensile strength, $f_{t}=0.35 f_{c u}^{0.55} ;$ ' $\rho_{\mathrm{f}}$ '= as FRP fiber distribution rate $\rho_{f}=\frac{2 w_{f} t_{f}}{b\left(w_{f}+s_{f}\right)}$; ' $\eta$ '= the paste area ratio FRP, $\eta=\frac{w_{f}}{w_{f}+s_{f}} ; ' \lambda$ '= the shear span ratio; ' $w_{\mathrm{f}}$ ', ' 't $\mathrm{f}_{\mathrm{f}}$ ' and ' $\mathrm{S}_{\mathrm{f}}$ ' are respectively the width, thickness and spacing of CFRP.

\section{conclusion}

1)Calculation formula in method 1 simplifies finite element calculation process, and can quickly assess the actual project in certain circumstance but its limitations are also relatively clear, such as its incompetence to react complete process of stress and strain etc.

2) Calculation formula in Method 2, using a known quantity for fitting CFRP effective strain, has a higher precision compared with method 1 .

3) Method 3 considers that strengthening beams usually occurs after one break and will experience the secondary load .The specific situation introduces the influence coefficient and is closer to actual engineering, But in view of the failure by different levels of first load, the bearing capacity of the beam recovery is also different, whether the influence coefficient can be unified consideration according to the method 3, what still needs further argument.

\section{References}

[1]G X, Yan, C H, Tong and L S, Zhang, 2011.CFRP formula of shear strength of reinforced concrete reinforcement. People the Yellow River, 33 (11), pp.128-132.

[2]J F Chen, J G Teng. Shear capacity of FRP-strengthened RC beams: FRP deboning $[\mathrm{J}]$.Construction and Building Materials, 2003, 17(1):27-41

[3]People's Republic of China ministry of construction, 2011, GB50010-2011 Design of Concrete Structures. Beijing: China Building Industry Press.

[4]Y Bai, 2009, Shear Capacity of CFRP Reinforced Concrete Beam. Shanxi Architecture, 35 (36), pp.58-59.

[5]Y P, Zhu, Y S Liao, J J Zheng, W C Teng and D D Zhao, 2011, CFRP Reinforced Concrete Beams Shear Experimental study. Sichuan Building Science, 37 (6), pp.92-95.

[6]Z Tan and L P Ye, 2003, Study on shear properties of fiber composites Reinforced concrete 
beams. Civil Engineering Education, 36 (11), pp.12-18.

[7]ECS, 2003, Carbonfiber sheet reinforced concrete structures technology, p.146.

[8]L S Zhang, E Q Fang and X Y Lin, 2004, CFRP damage in concrete structures reinforce entitle form of curved scissors analysis. Henan Science, 22 (5), pp.663-665. 